\title{
Studi Karakteristik Fraksi Olein Crude Palm Oil (CPO)
}

\author{
Study on Characteristics of Crude Palm Oil (CPO) Olein Fraction
}

\author{
Elisa Ginsel Popang, Winda Siringo-ringo, Muh. Yamin*, Mujibu Rahman, Andi Lisnawati, \\ Netty Maria Naibaho \\ Program Studi Teknologi Hasil Perkebunan, Politeknik Pertanian Negeri Samarinda, Indonesia. \\ *Corresponding Author: eligipo@gmail.com
}

\begin{abstract}
Abstrak
Luas lahan kelapa sawit di Indonesia pada tahun 2020 adalah $14.858 .300 \mathrm{Ha}$, sedangkan di Kalimantan Timur mencapai 1.378.136 Ha. Produk sawit yang cukup banyak dijumpai adalah Crude Palm Oil (CPO) memiliki ciri bewarna merah-kekuningant. CPO mempunyai sifat membeku pada suhu kamar dan mencair jika dipanaskan pada suhu di atas $65^{\circ} \mathrm{C}$, jika didiamkan akan terbentuk dua lapisan yakni lapisan minyak (olein) dan lapisan padat (stearin). Lapisan minyak (olein) biasanya berwarna merah, lapisan stearin berwarna kuning yang keduanya mengidikasikan memiliki kandungan nutrisi tertentu salah satunya adalah beta karoten. Tujuan penelitian ini adalah untuk mengetahui kadar air dan beta karoten fraksi olein CPO yang dihasilkan melalui pemanasan vakum. Penelitian dilakukan dalam dua tahap, yaitu pertama persiapan alat dan bahan yang akan digunakan kemudian tahap kedua adalah pemisahanan fraksi olein minyak sawit (CPO) dengan 3 perlakuan suhu rotary evapotar vakum yaitu suhu $60^{\circ} \mathrm{C}, 70^{\circ} \mathrm{C}$ dan $75^{\circ} \mathrm{C}$. Masing-masing perlakuan diulang sebanyak 3 kali. Parameter yang diamati meliputi kadar air dan kandungan beta karoten fraksi olein CPO. Kesimpulan dari penelitian ini adalah $\mathrm{P} 2$ (pemanasan pada suhu $70^{\circ} \mathrm{C}$ ) merupakan perlakuan yang terbaik dengan rata-rata kadar air 0,054\% dan rata-rata betakarotennya 592,00 ppm.
\end{abstract}

Kata kunci: Fraksi Olein CPO, beta karoten.

\begin{abstract}
The area of oil palm land in Indonesia in 2020 is $14,858,300 \mathrm{Ha}$, while in East Kalimantan it is 1,378,136 Ha. The common of Palm products in the market are Crude Palm Oil (CPO) which has red-yellow color characteristics. CPO has the property of freezing at room temperature and melting when heated at temperatures above $65^{\circ} \mathrm{C}$, if allowed to stand, two layers will form, namely an oil layer (olein) and a solid layer (stearin). The oil layer (olein) is usually red, the stearin layer is yellow, both of which indicate that it contains certain nutrients, one of which is beta carotene. The purpose of this study was to determine the water content and beta carotene of the CPO olein fraction produced by vacuum heating. The research was carried out in two stages, namely the first preparation of the tools and materials to be used then the second stage was the separation of the palm oil olein fraction (CPO) with 3 rotary evapotar vacuum treatments, namely $60^{\circ} \mathrm{C}, 70^{\circ} \mathrm{C}$ and $75^{\circ} \mathrm{C}$. Each treatment was repeated 3 times. Parameters observed included water content and beta carotene content of CPO olein fraction. The conclusion of this research is that P2 (heating at $70^{\circ} \mathrm{C}$ ) is the best treatment with an average water content of $0.054 \%$ and an average beta-carotene content of $592.00 \mathrm{ppm}$.
\end{abstract}

Keywords: CPO Olein Fraction, Beta carotene

\section{PENDAHULUAN}

Kelapa sawit merupakan tanaman perkebunan yang cukup penting di Indonesia dan masih memiliki prospek perkembangan yang cukup cerah. Komoditas kelapa sawit, baik berupa bahan mentah maupun hasil olahannya, menduduki peringkat ketiga penyumbang devisa terbesar bagi negara setelah kopi dan karet (Sastrosayono,2003). Luas lahan kelapa sawit di Indonesia pada tahun 2020 adalah 14.858.300 $\mathrm{Ha}$. Sedangkan di Kalimantan Timur hingga tahun 2020 luas areal kelapa sawit mencapai 1.378.136 $\mathrm{Ha}$ yang terdiri dari $373.479 \mathrm{Ha}$ sebagai tanaman plasma/ rakyat, $14.402 \mathrm{Ha}$ milik BUMN sebagai inti dan $912.030 \mathrm{Ha}$ milik Perkebunan Besar Swasta. Produksi TBS (Tandan Buah Segar) yang diolah pada tahun 2020 sebesar 17.723 .864 ton atau setara dengan 3,8 juta ton Crude Palm Oil (CPO). Potensi kelapa sawit (Crude Palm Oil dan Kernel Palm Oil) ada di Kaltim maka berpeluang untuk pengembangan industri hilir terutama olein, stearin dan lain-lain (Disbun Kaltim, 2021). 
Provinsi Kalimantan Timur memiliki 94 unit pabrik pengolahan minyak kelapa sawit yang sudah beroperasi yang memiliki kapasitas terpasang mencapai 5.005 ton dan kapasitas terpakai sebesar 4.337 ton (Sya'rawi, 2021)

Produk sawit yang cukup banyak dijumpai di Kalimantan Timur adalah Crude Palm Oil (CPO) memiliki ciri bewarna merahkekuningan merupakan hasil ektraksi dari buah kelapa sawit. CPO mempunyai sifat membeku pada suhu kamar dan mencair jika dipanaskan pada suhu di atas $65^{\circ} \mathrm{C}$, jika didiamkan akan terbentuk dua lapisan yakni lapisan minyak (olein) dan lapisan padat (stearin). Lapisan minyak (olein) biasanya berwarna merah, lapisan stearin berwarna kuning yang keduanya mengidikasikan memiliki kandungan nutrisi tertentu salah satunya adalah beta karoten.

Fraksi olein CPO dapat diperoleh dengan dua cara yaitu cara kimia dan cara fisik. Cara kimia biasanya menggunakan bahan kimia seperti asam fosfat dan soda caustik $(\mathrm{NaOH})$ untuk proses deguming dan netralizing. Cara fisik dapat dilakukan dengan cara mengendapkan, mengocok dan memutar dengan kecepatan tinggi sehingga akan terjadi dua lapisan yaitu cair di atas dan semi padat pada bagian bawah.

Kandungan retinol dalam fraksi olein mampu mencapai 15-300 kali dibandingkan wortel, sayuran, dan tomat, karena Minyak Sawit Merah mengandung 91,18\% karotenoid yang tinggi sehingga menyebabkan Fraksi Olein berwarna kemerahan. Kandungan tersebut antara lain $\alpha$-karoten $36,2 \%, \beta$-karoten $54,4 \%$, dan $\gamma$ karoten $3,3 \%$, likopen $3,8 \%$, dan xantofil 2,2\% (Sibuea, 2014).

Kandungan betakaroten dalam minyak sawit dipengaruhi oleh beberapa faktor, antara lain suhu dan waktu. Suhu yang terlalu tinggi dan lama proses deodorisasi yang kurang optimum dapat merusak kandungan beta karoten fraksi olein. Oleh karena itu perlu dilakukan penelitian tentang suhu dan lamanya pemanasan vakum terhadap fraksi olein.

Tujuan penelitian ini secara umum adalah untuk mengetahui kadar air dan beta karoten fraksi olein CPO yang dihasilkan melalui pemanasan vakum.

\section{METODE PENELITIAN}

\section{A. Bahan dan Peralatan}

Bahan-bahan yang digunakan dalam penelitian ini adalah CPO yang diperoleh dari salah satu pabrik kelapa sawit di Kalimantan Timur, fraksi olein CPO, aluminium foil dan reagen untuk analisa kimia. Peralatan yang dipergunakan dalam penelitian terdiri dari: rotary evaporator yang dilengkapi dengan pompa vakum, centrifuge, beaker gelas, gelas ukur, timbangan analitik, CPO meter, corong, oven, gegep, desikator, tabung reaksi dan botol kemasan.

\section{B. Rancangan Penelitian}

Rancangan penelitian yang digunakan dalam penelitian ini adalah Rancangan Acak Lengkap (RAL) dengan 3 perlakuan suhu rotary evapotar yaitu suhu $60^{\circ} \mathrm{C}, 70^{\circ} \mathrm{C}$ dan $75^{\circ} \mathrm{C}$. Masing-masing perlakuan diulang sebanyak 3 kali.

\section{Tahap Penelitian}

Penelitian dilakukan dalam dua tahap, yaitu pertama persiapan alat dan bahan yang akan digunakan dalam penelitian kemudian tahap kedua adalah pemisahanan fraksi olein minyak sawit (CPO).

Adapun tahapan adalah sebagai berikut:

1. Disiapkan CPO sebanyak $1000 \mathrm{ml}$

2. Dihitung terlebih dahulu kadar air dan betakaroten $\mathrm{CPO}$ yang akan digunakan.

3. CPO dimasukkan kedalam tabung centrifuge untuk proses pemisahan (fraksinasi) dengan kecepatan $4000 \mathrm{rpm}$ selama 3 menit.

4. Fraksi olein (bagian atas) dipisahkan dengan stearin (bagian bawah).

5. Fraksi olein CPO diaduk agar tercampur merata.

6. Fraksi olein CPO dianalisa kadar air dan $\beta$-karotennya.

7. Dipanaskan dalam rotari evaporator sesuai suhu perlakuan selama 2 jam dan tekanan vakum $108 \mathrm{Mpa}, 50 \mathrm{rpm}$.

8. Dianalisa kadar air dan $\beta$-karoten.

\section{Parameter yang Diamati}

Kadar Air, Metode Oven (SNI 01-3555, 1998)

Cawan porselin dipanaskan di dalam oven dengan suhu $105^{\circ} \mathrm{C}$ selama satu jam, 
kemudian didinginkan dalam desikator selama 30 menit. Lalu bobotnya ditimbang dan dicatat. Setelah itu, sampel minyak ditimbang sebanyak 5 gram pada cawan porselin yang telah dikeringkan dan selanjutnya dipanaskan dalam oven pada suhu $105^{\circ} \mathrm{C}$ selama 30 menit. Kemudian sampel didinginkan dalam desikator selama 30 menit. Cawan poselin yang berisi sampel minyak lalu ditimbang. Pemanasan dan penimbangan diulangi sampai diperoleh bobot tetap. Kadar air dinyatakan sebagai persen bobot per bobot, dihitung sampai dua desimal dengan rumus:

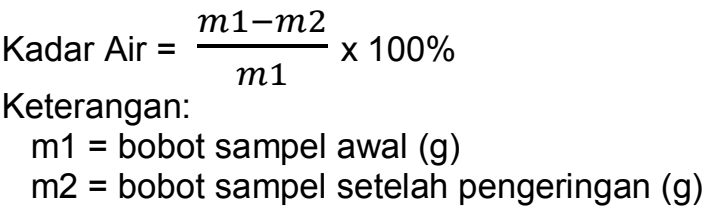

\section{Betakaroten}

Pengukuran betakaroten sampel Fraksi Olein CPO menggunakan alat Palm Oil Tester.

\section{E. Analisis Statistik}

Data yang diperoleh selanjutnya dianalisis secara statistik menggunakan Analisis of Varians (ANOVA) pada taraf uji $5 \%$ dan $1 \%$. Apabila terjadi beda nyata dilakukan uji lanjutan dengan uji LSD (Least Significance Different) pada taraf 5\%.

\section{HASIL DAN PEMBAHASAN}

\section{A. Kadar Air dan Karotenoid Awal}

Kandungan bahan baku CPO (Crude Palm Oil) dan FO (Fraksi Olein) terlebih dahulu diukur untuk mengetahui kondisi awal bahan baku. Hasil pengukuran bahan baku menunjukkan kadar air CPO sekitar $1.15 \%$ dan kandungan karotenoid sebesar 670.3 ppm; sedangkan untuk FO kadar airnya sebesar $0.07 \%$, kandungan karotenoid sebesar 654.8 ppm. Bahan baku CPO dan FO mengandung karotenoid yang cukup tinggi. Minyak sawit kasar atau CPO merupakan salah satu sumber karoten tertinggi yang diekuivalenkan dengan retinol (pro-vitamin A). Kandungan karoten minyak sawit berbeda menurut varietas dan kematangan buah. Kandungan karotenoid
CPO dari varietas Tenera berkisar antara 500-700 ppm, sedangkan varietas Dura yang berasal dari Nigeria berkisar antara 800-1600 ppm (Naibaho, 1998).

\section{B. Kadar Air Fraksi Olein CPO}

Dari hasil penelitian diperoleh bahwa fraksi olein CPO dengan perlakuan pemanasan vakum suhu $60^{\circ} \mathrm{C}$ menghasilkan rata-rata kadar air tertinggi yakni sebesar $0.063 \%$, selanjutnya pada perlakuan pemanasan vakum suhu $70^{\circ} \mathrm{C}$ sebesar $0.054 \%$ dan terendah dihasilkan oleh perlakuan pemanasan vakum suhu $75^{\circ} \mathrm{C}$ sebesar $0.044 \%$. Rata-rata kadar air fraksi olein CPO setelah pemanasan vakum dengan suhu berbeda dapat dilihat pada Tabel 1 berikut:

Tabel 1. Nilai Rata-Rata Kadar Air (\%) Fraksi Olein CPO

\begin{tabular}{ccccc}
\hline \multirow{2}{*}{ Perlakuan } & \multicolumn{3}{c}{ Ulangan } & $\begin{array}{c}\text { Rata- } \\
\text { rata }\end{array}$ \\
\cline { 2 - 4 } & 1 & 2 & 3 & 0.063 \\
P1 & 0.066 & 0.060 & 0.064 & 0.054 \\
P2 & 0.057 & 0.054 & 0.052 & 0.054 \\
P3 & 0.043 & 0.043 & 0.046 & 0.044 \\
\hline
\end{tabular}

Keterangan:

$\mathrm{P} 1=$ Suhu $60^{\circ} \mathrm{C}$, tekanan $108 \mathrm{Mpa}, 50 \mathrm{rpm}$ selama $2 \mathrm{jam}$ $\mathrm{P} 2=$ Suhu $70^{\circ} \mathrm{C}$, tekanan $108 \mathrm{Mpa}, 50 \mathrm{rpm}$ selama $2 \mathrm{jam}$ $\mathrm{P} 3=$ Suhu $75^{\circ} \mathrm{C}$, tekanan $108 \mathrm{Mpa}, 50 \mathrm{rpm}$ selama $2 \mathrm{jam}$

Hasil penelitian menunjukkan bahwa semakin tinggi suhu pemvakuman fraksi olein CPO menghasilkan kadar air yang semakin kecil, hal ini dapat disebabkan besarnya suhu dan tekanan yang dapat mempercepat laju keluarnya air dari minyak. Ketiga perlakuan menunjukan kadar air yang kecil, yang berarti memberikan dampak yang baik pada produk minyak.

Menurut Ketaren (1996), jika dalam minyak terdapat air maka akan mengakibatkan reaksi hidrolisis yang dapat menyebabkan kerusakan minyak, menyebabkan rasa dan bau tengik pada minyak, air yang ada dalam minyak dapat juga dijadikan sebagai media pertumbuhan mikroorganisme yang dapat menghidrolisis minyak.

Untuk mempercepat penguapan air serta menghindari terjadinya reaksi yang menyebabkan terbentuknya air ataupun reaksi yang lain karena pemanasan maka dapat dilakukan pemanasan dengan suhu 
rendah dan tekanan vakum (Sudarmadji dkk., 1989).

Nilai kadar air fraksi olein sebelum pemanasan vakum adalah $0,07 \%$. Setelah pemanasan vakum, nilai kadar air fraksi olein mengalami pengurangan. Pada perlakuan P1 dengan suhu $60^{\circ} \mathrm{C}$ selama 2 jam kadar air yang berkurang $1 \%$, Pada perlakuan P2 dengan suhu $70^{\circ} \mathrm{C}$ selama 2 jam kadar air yang berkurang $2 \%$ dan pada perlakuan $\mathrm{P} 3$ dengan suhu $75^{\circ} \mathrm{C}$ selama 2 jam kadar air berkurang 3\% dari kadar air awal sebelum pemanasan vakum. Semakin tinggi suhu yang digunakan maka kadar air yang berkurang semakin besar.

Berdasarkan hasil Uji Anova pada tarf $1 \%$, menunjukkan bahwa suhu rotary evaporator vakum berpengaruh sangat nyata terhadap kadar air Fraksi Olein CPO yang dihasilkan. Sehingga uji statistik dilanjutkan dengan uji LSD (Least Significance Different) pada taraf $5 \%$.

Tabel 2. Hasil Uji LSD Nilai Rata-Rata Kadar Air (\%) Fraksi Olein CPO

\begin{tabular}{ccc}
\hline Perlakuan & Rata-rata & Notasi \\
\hline P1 & 0.063 & $\mathrm{a}$ \\
P2 & 0.054 & $\mathrm{ab}$ \\
P3 & 0.044 & $\mathrm{~b}$
\end{tabular}

Hasil Uji LSD menunjukkan bahwa perlakuan $\mathrm{P} 1$ tidak berbeda nyata dengan $\mathrm{P} 2$ tetapi berbeda nyata dengan perlakuan P3. Perlakuan P2 tidak berbeda nyata dengan perlakuan $\mathrm{P} 3$.

\section{Kandungan $\beta$-KAROTEN (ppm) Fraksi Olein CPO}

Dari hasil penelitian diperoleh bahwa kandungan $\beta$ - karoten fraksi olein CPO dengan perlakuan pemanasan vakum suhu $60^{\circ} \mathrm{C}$ menghasilkan rata-rata kandungan $\beta$ karoten tertinggi yakni sebesar $618,10 \mathrm{ppm}$, disusul oleh perlakuan pemanasan vakum suhu $70^{\circ} \mathrm{C}$ sebesar $592,00 \mathrm{ppm}$ dan terendah dihasilkan oleh perlakuan pemanasan vakum suhu $75^{\circ} \mathrm{C}$ sebesar $574,77 \mathrm{ppm}$. Perlakuan pemanasan vakum berbeda pada fraksi olein CPO mengindikasikan adanya aktivitas penurunan kandungan $\quad \beta$-karoten $(\mathrm{ppm}) \quad$ jika dibandingkan dengan kandungan $\beta$-karoten fraksi olein CPO sebelum dilakukan perlakuan pemanasan vakum, dimana sebelum pemanasan vakum kandungan $\beta$ karoten fraksi olein CPO sebesar 654,8 ppm. Penurunan kandungan $\beta$-karoten fraksi olein CPO tertinggi diperoleh pada pemanasan vakum suhu $75^{\circ} \mathrm{C} \mathrm{P} 3$ sebesar $80,03 \mathrm{ppm}$ dan terendah pada pemanasan vakum suhu $60^{\circ} \mathrm{C}$ (P1) sebesar 36,7 ppm. Rata-rata kandungan $\beta$-karoten dengan tingkat suhu vakum berbeda dapat dilihat pada Tabel 3 berikut:

Tabel 3. Nilai Rata-Rata $\beta$-karoten (ppm) Fraksi Olein CPO

\begin{tabular}{ccccc}
\hline \multirow{2}{*}{ Perlakuan } & \multicolumn{3}{c}{ Ulangan } & $\begin{array}{c}\text { Rata- } \\
\text { rata }\end{array}$ \\
\cline { 2 - 4 } & 1 & 2 & 3 & 618.10 \\
P1 & 634.4 & 610.0 & 609.9 & 610 \\
P2 & 592.0 & 595.4 & 588.6 & 592.00 \\
P3 & 568.2 & 578.7 & 577.4 & 574.77 \\
\hline
\end{tabular}

Keterangan:

$\mathrm{P} 1=$ Suhu $60^{\circ} \mathrm{C}$, tekanan $108 \mathrm{Mpa}, 50 \mathrm{rpm}$ selama 2 jam $\mathrm{P} 2=$ Suhu $70^{\circ} \mathrm{C}$, tekanan $108 \mathrm{Mpa}, 50 \mathrm{rpm}$ selama $2 \mathrm{jam}$ $\mathrm{P} 3=$ Suhu $75^{\circ} \mathrm{C}$, tekanan $108 \mathrm{Mpa}, 50 \mathrm{rpm}$ selama $2 \mathrm{jam}$

Ketiga perlakuan menunjukkan terjadinya penurunan kandungan $\beta$-karoten pada fraksi olein CPO sebagai akibat dari pemanasan vakum, namun demikian kandungan $\beta$-karoten fraksi olein pada penelitian ini masih cukup tinggi. Hasil ini didukung oleh Priatni dkk. (2017) yang menyatakan bahwa suhu berpengaruh nyata terhadap kandungan betakaroten. Menurut Satriyanto dkk. (2012), kenaikan suhu dan lama pemanasan dapat menyebabkan peningkatan komponen. Akan tetapi suhu yang terlalu tinggi juga dapat menyebabkan kerusakan pada bahan yang sedang diproses. Menurunnya kandungan karotenoid disebabkan karena terjadinya kerusakan senyawa karitenoid akibat peningkatan suhu.

Adapun kandungan betakaroten fraksi olein awal sebelum pemanasan vakum yaitu 654,8. Setelah pemanasan vakum, kandungan betakaroten fraksi olein menjadi berkurang. Pada P1 dengan suhu pemanasan vakum $60^{\circ} \mathrm{C}$ selama 2 jam, kandungan betakaroten fraksi olein adalah $90 \%$ dari karoten awal. Pada P2 dengan suhu pemanasan vakum $70^{\circ} \mathrm{C}$ selama 2 jam kadar betakaroten adalah $80 \%$ dari kadar betakaroten awal dan P3 dengan suhu pemanasan vakum $75^{\circ} \mathrm{C}$ selama 2 jam menghasilkan fraksi olein dengan kadar betakaroten $70 \%$ dari kadar betakaroten awal. Hal ini menunjukkan bahwa semakin tinggi suhu pemanasan vakum fraksi olein, 
semakin banyak kadar betakaroten yang hilang.

Berdasarkan hasil Uji Anova pada tarf $1 \%$, menunjukkan bahwa suhu rotary evaporator vakum berpengaruh sangat nyata terhadap betakaroten Fraksi Olein CPO yang dihasilkan. Sehingga uji statistik dilanjutkan dengan uji LSD (Least Significance Different) pada taraf $5 \%$.

Tabel 4. Hasil Uji LSD Nilai Rata-Rata $\beta$-karoten (ppm) Fraksi Olein CPO

\begin{tabular}{ccc}
\hline Perlakuan & Rata-rata & Notasi \\
\hline P1 & 618.10 & a \\
P2 & 592.00 & b \\
P3 & 574.77 & b \\
\hline
\end{tabular}

Hasil Uji LSD menunjukkan bahwa perlakuan P1 berbeda nyata dengan perlakuan P2 dan P3, tetapi perlakuan P2 tidak berbeda nyata dengan perlakuan P3.

\section{KESIMPULAN}

Berdasarkan hasil yang diperoleh, dapat ditarik kesimpulan sebagai berikut:

1. Kadar air terendah terdapat pada fraksi olein yang dipanaskan dengan suhu $75^{\circ} \mathrm{C}$ yaitu 0,044\%.

2. Kandungan betakaroten tertinggi terdapat pada fraksi olein yang dipanaskan dengan suhu $60^{\circ} \mathrm{C}$ yaitu $618,10 \mathrm{ppm}$.

3. Dari hasil Uji LSD dapat disimpulkan bahwa Perlakuan yang terbaik adalah P2 yaitu pemanasan pada suhu $70^{\circ} \mathrm{C}$ dengan rata-rata kadar air $0,054 \%$ dan rata-rata betakarotennya 592,00 ppm.

\section{UCAPAN TERIMA KASIH}

Penulis mengucapkan terimakasih
kepada Politeknik Pertanian Negeri
Samarinda Jurusan Teknologi Pertanian
yang telah memfasilitasi penelitian ini melalui
penyediaan laboratorium dan kepada semua
pihak yang telah membantu dalam penelitian
ini.

\section{DAFTAR PUSTAKA}

Dinas Perkebunan Kalimantan Timur, 2021. Sejarah Singkat Sawit di Kalimantan Timur. Gatra.Com, Samarinda.

Ketaren, S., 2005. Mnyak dan Lemak Pangan. Universitas Indonesia (UIPress), Jakarta.

Naibaho, P.M., 1998. Teknologi Pengolahan Kelapa Sawit. Pusat Penelitian Kelapa Sawit, Medan.

Priatni, A., Fauziati. Dan Yuni A., 2017. Ekstraksi Karotenoid Dari Minyak Sawit Mentah (CPO) Dengan Pelarut Dietil Eter Dan Aceton. Jurnal Riset Teknologi Industri Vol.11, No.2.

Robiyansyah, A.,Zuidar S. dan Hidayati S. 2017. Pemanfaatan Minyak Sawit Merah dalam Pembuatan Biskuit Kacang Kaya Betakaroten. Jurnal Teknologi Industri dan Hasil Pertanian Vol.22, No. 2: 201212.

Sastrosayono, S., 2003. Budidaya Kelapa Sawit. Agromedia Pustaka, Jakarta.

Satriyanto, B., Simon B. W. dan Yunianta, 2012. Stabilitas Warna Ekstrak Buah Merah (Pandanus conoideus) Terhadap Pemanasan Sebagai Sumber Potensial Pigmen Alami. Jurnal Teknologi Pertanian Vol. 13 No. 3 Hal. 157-168.

Sibuea, P., 2014. Minyak Kelapa Sawit. Erlangga, Jakarta.

Standar Nasional Indonesia (SNI). 1998. Cara Uji Minyak dan Lemak. Badan Standardisasi Nasional, Jakarta. (SNI 01-3555-1998).

Sudarmadji, S., B. Haryono dan Suhardi. 1989. Analisa Bahan Makanan dan Pertanian. Liberty, Yogyakarta.

Sumarna, 2014. Studi Metode Pengolahan Sawit Merah (Red Palm Oil) Dari Crude Palm Oil (CPO). Jurusan Teknologi Hasil Pertanian. Universitas Mulawarman, Samarinda.

Sya'rawi, M.M. 2021. Kaltim Hingga Saat ini Miliki 94 Pabrik Kelapa Sawit. Bisnis.com, Samarinda. https://kalimantan.bisnis.com/read/2021 0414/408/1381115/kaltim-hingga-saatini-miliki-94-pabrik-kelapa-sawit. 